\title{
A Sensorless Vector Control Using new BS_PCH Controller structure and SC MRAS Adaptive Speed Observer for Electric Vehicles
}

\author{
NGOC THUY PHAM ${ }^{1 *}$, THUAN DUC LE ${ }^{1}$ \\ Dept. of Electrical Engineering Technology \\ Industrial University of Ho Chi Minh City \\ VIETNAM
}

\begin{abstract}
In this paper, a new controll structure are proposed to sensorless vector control the in-wheel motor drive system of Electric Vehicle (EV) to improve its performance and robustness. The design of the controller is based on Backstepping and Hamitolnion control combined with a improved stator current MRAS adaptive speed observer proposed to estimate the vehicle speed and it also can compensate for the uncertainties caused by the machine parameter variations, measurement errors, and load disturbances, improving dynamic performance and enhancing the robustness of the SPIM drive system, perfect tuning of the speed reference values, fast response of the motor current and torque, high accuracy of speed regulation. A global EV model is also evaluated based on the vehicle dynamics in this paper. The simulation results lead to the conclusion that the proposed system for the propulsion system of electric vehicle is feasible. The simulation results on a test vehicle propelled by two SPIM showed that the proposed control approach operates satisfactorily.
\end{abstract}

Key-Words: - Backstepping control, Port Controlled Hamiltonian control, stator current MRAS, neuron network, SPIM.

Received: January 2, 2020. Revised: May 31, 2020. Re-revised: July 15, 2020. Accepted: August 18, 2020. Published: September 11, 2020.

\section{Introduction}

In recent years, due to the effect of the greenhouse effect and the lack of fossil energy, a lot of research efforts have focused on developing high quality and efficient EV drive system such as a solution to energy and environmental issues. Electric motor drive is one of the main technologies in EV. An EV is driven by the electric motor, in addition to being environmentally friendly, it also has the advantage of creating a torque that responds quickly and accurately [1-4]. Electric drive system in EV includes: electric motors, converters and controllers. This system is designed to meet the speed and torque requirements set by the driver. For motors used in EVs, SPIM is one of the most competitive proposals for propulsion systems in EVs due to their outstanding advantages such as fault tolerance, reduced phase current $1 / 2$ with the same source. pressure applied to motors compared to three-phase motors of the same capacity, high torque, low torque, vibration and noise reduction, high efficiency due to reduced rotor current, [5] ...

In order to improve the performance of the drive system in the EV, many modern control solutions have been developed such as the field oriente control (FOC), direct torque control (DTC), and model predict control (MPC). However, both DTC and MPC need to analyze and select the vector voltage, the number of these voltage vectors increases exponentially as the number of stator phases increases. With its advantages, FOC Control Technology is the dominant control solution currently applied in the drive system for electric vehicle [6-7]. However, the conventional FOC strategies using PI control cannot provide satisfactory quality for high performance drives. In order to overcome these, recently nonlinear control methods have been developed to replace PID controllers such as [8-18]: Regulatory linear control, sliding mode control, Backstepping control, Fuzzy Logic control and neural network control, prediction control, passive control, Hamiltonia control,.v..v. However, these nonlinear control techniques are usually quite complex, demanding high computational effort, and requiring a precise mathematical model. They were difficult to obtain satisfactory control performance when using independently, especially in the cases applied to control the nonline systems. Therefore, the combination different control techniques to both simple and enhance the performance of SPIM drives, such as combined [19-21] to get a effective control system. In this paper, the author proposes a 
combined control structure using BS controller for outer speed control, SPIM parameters are updated for controller to minimizing the effect of changing the parameters on the efficiency of the controller. The PCH controller is proposed for inner current controller to enhance the performance of the inwheel motor drive system of Electric Vehicle. Beside, to reduce the parameter sensitivity, noise, cost, size, weight and increase the reliability of the system [22], a speed observer instead the mechanical sensors is proposed. In the proposed observer, the reference model uses the stator current components to free of pure integration problems and insensitive to motor parameter variations. In this scheme are, first: Adaptive model uses a two layer linear neural network trained online by a BPN algorithm. Second, the rotor flux is identified by the (VM) Voltage Model with the Rs value is estimated online to enhance the performance of the proposed observer, in addition, using VM will avoid the instability in the regenerating mode. The effectiveness of this proposed schemes for controlling the in-wheel motor drive system of Electric Vehicle is verified by simulation using MATLAB/ Simulink.

The paper is organized into five sections, in section 2 , the basic theory of the model of the SPIM and the SPIM drive are presented. Section 3 introduces BS PCH controller and proposed observer. Simulation and discuss are presented in Section 4. Finally, the concluding is provided in Section 5.

\section{Model of SPIM and electric propulsion system in $\mathrm{EV}$}

\subsection{Model of SPIM}

The SPIM drive system scheme is provided in Fig.1. The original six-dimensional space of the machine is transformed into three two-dimensional orthogonal subspaces in the stationary reference frame (D-Q), ( $\mathrm{x}-\mathrm{y})$ and $(\mathrm{zl}-\mathrm{z} 2)$ based on the Vector Space Decomposition (VSD) technique [9]. This transformation is obtained by means of $6 \times 6$ transformation matrix (Eq.1).

$$
T_{6}=\frac{1}{3}\left[\begin{array}{cccccc}
1 & -\frac{1}{2} & -\frac{1}{2} & \frac{\sqrt{3}}{2} & -\frac{\sqrt{3}}{2} & 0 \\
0 & \frac{\sqrt{3}}{2} & -\frac{\sqrt{3}}{2} & \frac{1}{2} & \frac{1}{2} & -1 \\
1 & -\frac{1}{2} & -\frac{1}{2} & -\frac{\sqrt{3}}{2} & \frac{\sqrt{3}}{2} & 0 \\
0 & -\frac{\sqrt{3}}{2} & \frac{\sqrt{3}}{2} & \frac{1}{2} & \frac{1}{2} & -1 \\
1 & 1 & 1 & 0 & 0 & 0 \\
0 & 0 & 0 & 1 & 1 & 1
\end{array} \mid\right.
$$

The electrical matrix equations in the stationary reference frame for the stator and the rotor may be written as ( Eq.2)

$$
\begin{aligned}
& {\left[V_{s}\right]=\left[R_{s}\right]\left[I_{s}\right]+p\left(\left[L_{s s}\right]\left[I_{s}\right]+\left[L_{s r}\right]\left[I_{r}\right]\right)} \\
& {[0]=\left[R_{r}\right]\left[I_{r}\right]+p\left(\left[L_{r r}\right]\left[I_{r}\right]+\left[L_{r s}\right]\left[I_{s}\right]\right)}
\end{aligned}
$$

where: $[\mathrm{V}],[\mathrm{I}],[\mathrm{R}],[\mathrm{L}]$ and $[\mathrm{Lm}]$ are voltage, current, resistant, self and mutual inductance vectors, respectively. $\mathrm{P}$ is differential operator. Subscript $r$ and $s$ related to the rotor and stator resistance respectively. Since the rotor is squirrel cage, $[\mathrm{Vr}]$ is equal to zero. The electromechanical energy conversion only takes place in the DQ subsystem:

$$
\left[\begin{array}{c}
V_{s \alpha} \\
V_{s \beta} \\
0 \\
0
\end{array}\right]=\left[\begin{array}{cccc}
R_{s}+P L_{s} & 0 & P L_{m} & 0 \\
0 & R_{s}+P L_{s} & 0 & P L_{m} \\
P L_{m} & \omega_{r} L_{m} & R_{r}+P L_{r} & \omega_{r} L_{r} \\
-\omega_{r} L_{m} & P L_{m} & -\omega_{r} L_{m} & R_{r}+P L_{r}
\end{array}\right]\left[\begin{array}{c}
I_{s \alpha} \\
I_{s \beta} \\
I_{r \alpha} \\
I_{r \beta}
\end{array}\right]
$$

where $\delta \mathrm{r}$ is the rotor angular position referred to the stator as shown in Fig. 1. To control for SPIM drives in $\mathrm{EV}$, a transformation matrix must be used to represent the stationary reference fame $(\alpha-\beta)$ in the dynamic reference $(\mathrm{d}-\mathrm{q})$. This matrix is given:

$$
T_{2}=\left[\begin{array}{cc}
\cos \left(\delta_{r}\right) & -\sin \left(\delta_{r}\right) \\
\sin \left(\delta_{r}\right) & \cos \left(\delta_{r}\right)
\end{array}\right]
$$

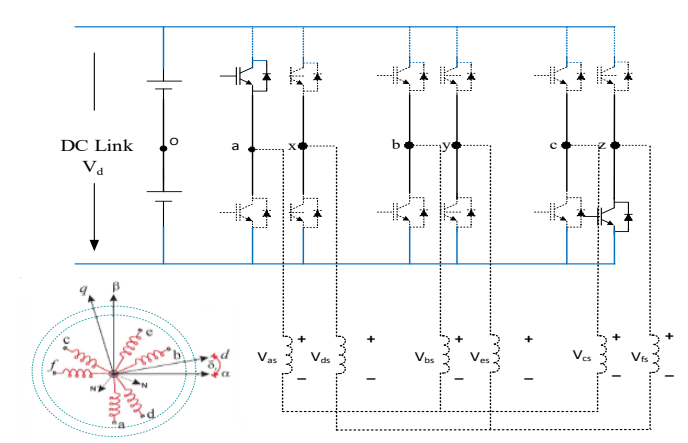

Figure. 1. A SPIM drive general diagram

\subsection{Model of electric propulsion system}

In the FOC control case for SPIM, we have: $\psi_{\mathrm{rq}}=0$, $\psi_{\mathrm{rd}}=\psi_{\mathrm{rd}}$. The equation of the SPIM drive in the rotary reference coordinates can be written as follows

$$
\left\{\begin{array}{l}
L_{s} \frac{d i_{s d}}{d t}=-a i_{s d}+L_{s} \omega_{e} i_{s q}+b R_{r} \psi_{r d}+c u_{s d} \\
L_{s} \frac{d i_{s q}}{d t}=-a i_{s q}+L_{s} \omega_{e} i_{s d}+b_{r} \omega_{e} \psi_{r d}+c u_{s q} \\
\frac{d \omega_{r}}{d t}=\frac{3}{2} P \frac{\delta \sigma L_{s}}{J}\left(\psi_{r d} i_{s q}\right)-\frac{T_{L}}{J}-B \omega_{r} \\
\frac{d \psi_{r d}}{d t}=\frac{L_{m}}{\tau_{r}} i_{s d}-\frac{1}{\tau_{r}} \psi_{r d}
\end{array}\right.
$$




$$
\sigma=1-\frac{L_{m}^{2}}{L_{s} L_{r}} ; \delta=\frac{L_{m}}{\sigma L_{s} L_{r}} ; a=\frac{L_{m}^{2} R_{r}+L_{r}^{2} R_{s}}{\sigma L_{r}^{2}} ; b=\frac{L_{m}^{2} R_{r}}{\sigma L_{r}^{2}} ; c=\frac{1}{\sigma} ; \tau_{r}=\frac{L_{r}}{R_{r}}
$$

The electromagnetic torque and the slip frequency can be expressed in dq reference frame:

$$
\begin{aligned}
& T_{e}=\frac{3}{2} n_{p} \frac{L_{m}}{L_{r}} \psi_{r d} i_{s q} \\
& \omega_{s l}=\frac{L_{m}}{L_{r}} \psi_{r d} i_{s q}
\end{aligned}
$$

We also have:

$$
T_{e}=T_{L}+B \omega_{r}+J \frac{d \omega_{r}}{d t}
$$

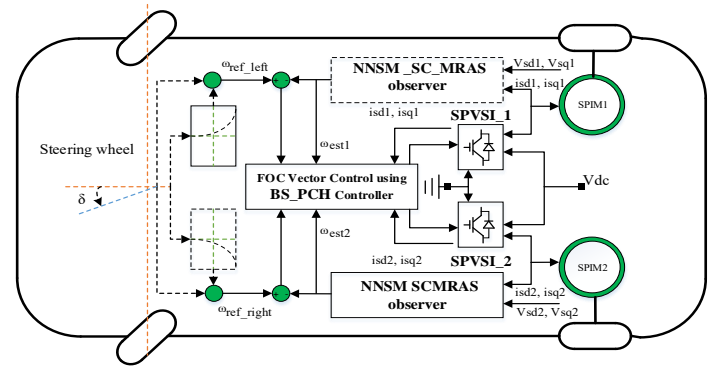

Fig 2: The diagram of proposed drive in $\mathrm{EV}$

To propel EV, SPIM must supply the torque to the wheels. Need to consider the major factors influence to the EV dynamics model such as the road condition, hill climbing and acceleration aerodynamic drag, etc.,. In this proposed control strategy takes into account vehicle aerodynamics. This model is based on the principles of vehicle mechanics and aerodynamics [24]. The total tractive effort is then given by

$$
\begin{aligned}
F_{t e} & =F_{r r}+F_{h c}+F_{a d}+F_{l a}+F_{w a} \\
& » m_{r r} m g+m g \sin f+\frac{1}{2} r A C_{d} v^{2}+m \frac{d v}{d t}+F_{L}
\end{aligned}
$$

where, F: Tractive force; Frr: Rolling resistance force; Fhc: Hill climbing force; Fla: Linear acceleration force; Fwa: Angular acceleration force; $\mathrm{m}$ is the mass of $\mathrm{EV}$; $\mathrm{g}$ is the gravity acceleration; $\mathrm{v}$ is the vehicle velocity; $\mu_{r r}$ is the rolling resistance coefficient; $r$ is the air density; $A$ is the frontal area of LEV; $C d$ is the drag coefficient; $f$ is the hill climbing angle; $F L$ is the external disturbances term; $r$ is the tyre radius of $\mathrm{LEV} ; \mathrm{G}$ is the gear ratio; $\mathrm{T}$ is the required torque of LEV; vr is the motor speed of in-wheel motor using SPIM. In Fig. 3, when using the field-oriented control scheme, the electromagnetic torque $\mathrm{Te}$ can be expressed simply as

$T_{m}=\frac{r F_{t e}}{G}$

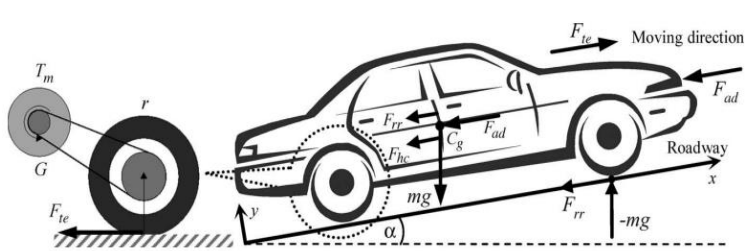

Fig. 3 Elementary forces acting on a vehicle [26]

The power required to drive a vehicle at a speed $\mathrm{v}$ has to compensate for counteracting forces

$$
P=v F_{t e}=v\left(m_{r r} m g+m g \sin f+\frac{1}{2} r A C_{d} v^{2}+m \frac{d v}{d t}+F_{L}\right)
$$

when using the field-oriented control scheme, the electromagnetic torque $\mathrm{Te}$ can be expressed simply as

$$
T_{e}=K_{t} i_{s q}
$$

where $K_{t}$ is the torque coefficient; $i_{s q}$ is the q-axis torque current command.

From the vehicle dynamic model shown in (1)-(3), the required torque of a single in-wheel motor $\mathrm{T}$ motor can be shown as

$$
\frac{T_{m}}{n}=T_{\text {motor }}=K_{t} i_{s q}
$$

where $i_{s q}$ is the required torque current command; $\mathrm{n}$ is the number of in-wheel motor drive. The torque equation of an in-wheel motor is as follows

$$
\begin{aligned}
T_{e} & =J \frac{d \omega_{r}}{d t}+B \omega_{r}+T_{\text {motor }} \\
& =J \frac{d \omega_{r}}{d t}+B \omega_{r}+\frac{T_{m}}{n}
\end{aligned}
$$

where $J$ is the inertia of the in-wheel motor using SPIM including the tyre set; $B$ is the viscous coefficient. Moreover, assuming the system parameter variations of the SPIM are absent, then the overall vehicle dynamic model of EV system including the torque equation of the PMSM can be written as

$$
\begin{gathered}
T_{e}=\left(J+m \frac{r^{2}}{n G^{2}}\right) \frac{d \omega_{r}}{d t}+B \omega_{r}+\frac{r}{n G}\left(\mu_{r r} m g+\frac{1}{2} \rho A C_{d} v^{2}+m g \sin \phi+F_{L}\right) \\
=\left(J+m \frac{r^{2}}{n G^{2}}\right) \frac{d \omega_{r}}{d t}+B \omega_{r}+T_{L}
\end{gathered}
$$

where $T_{L}$ is the load torque including the effects of rolling resistance, air drag, hill climbing and external disturbances, and the overbar symbol represents the system parameter in the nominal condition. 


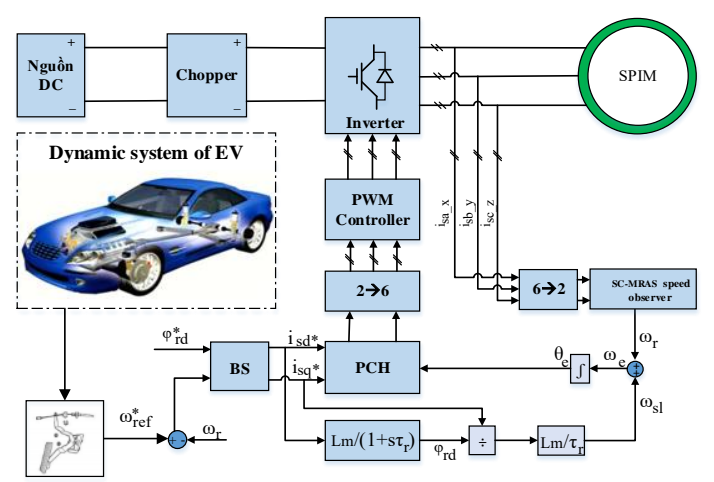

Fig. 4 The proposed drive for EV propulsion system

\section{The proposed sensorless vector} control scheme for SPIM drives in EV propulsion system.

\subsection{The proposed BS controller for outer speed control and rotor flux loops}

As we known, the speed response depends on the inertia of the machine. Therefore, if a fast acting controller is used into the outer speed of vector control of SPIM drives, it can always provide $i_{\mathrm{sq}}$ reference current in excess the allowed limit and then the controllers will default work at the critical value. In other words, the output of the speed and rotor loop always work on saturated modes at the limit values, the working time in these modes depend on the sudden change in reference speed and the time constant due to inertia mechanics of the machine. These make the system lost control whenever the controller reaches saturation. To overcome this, the BS controller is proposed, it is quite good from a mechanical mechanic point of view. The stability and performance of the subsystems is studied by Lyapunov theory. Therefore, at each step of the design, a virtual command is created to ensure the convergence of subsystems.

$$
\begin{aligned}
& \varepsilon_{\omega}=\left(\omega_{r}^{*}-\omega_{r}\right)+k_{\omega} \int_{0}^{t}\left(\omega_{r}^{*}-\omega_{r}\right) d t \\
& \varepsilon_{\psi}=\left(\psi_{r d}^{*}-\psi_{r d}\right)+k_{\psi}^{\prime} \int_{0}^{t}\left(\psi_{r d}^{*}-\psi_{r d}\right) d t
\end{aligned}
$$

The error dynamical equations are

$$
\begin{aligned}
& \dot{\varepsilon}_{\omega}=\dot{\omega}_{r}^{*}-\frac{3}{2} P \frac{\delta \sigma L_{s}}{J} \psi_{r d} i_{s q}+\frac{T_{l}}{J}+B \omega_{r}+k_{\omega}^{\prime}\left(\omega_{r}^{*}-\omega_{r}\right) \\
& \dot{\varepsilon}_{\psi}=\dot{\psi}_{r d}^{*}+\frac{L_{m}}{\tau_{r}} i_{s d}+\frac{1}{\tau_{r}} \psi_{r d}+k_{\psi}^{\prime}\left(\psi_{r d}^{*}-\psi_{r d}\right)
\end{aligned}
$$

To obtain the virtual controller of speed and rotor flux loop, the following Lyapunov function candidate is considered:

$$
V_{(\omega, \psi)}=\frac{1}{2}\left(\varepsilon_{\omega}^{2}+\varepsilon_{\psi}^{2}\right)
$$

Differentiating $V$ :

$$
\begin{aligned}
& \frac{d V_{(\omega, \psi)}}{d t}=\varepsilon_{\omega} \frac{d \varepsilon_{\omega}}{d t}+\varepsilon_{\psi} \frac{d \varepsilon_{\psi}}{d t} \\
& =\varepsilon_{\omega}\left[\frac{d \omega_{r}^{*}}{d t}-\frac{3}{2} n_{p} \frac{\delta \sigma L_{s}}{J} \psi_{r d} i_{s q}^{*}+\frac{T_{l}}{J}+B \omega_{r}+k_{\omega}^{\prime}\left(\omega_{r}^{*}-\omega_{r}\right)\right] \\
& +\varepsilon_{\psi}\left[\frac{d \psi_{r d}^{*}}{d t}+\frac{L_{m}}{\tau_{r}} i_{s d}^{*}+\frac{1}{\tau_{r}} \psi_{r d}+k_{\psi}^{\prime}\left(\psi_{r d}^{*}-\psi_{r d}\right)\right]
\end{aligned}
$$

where: $k_{\omega}^{\prime}, k^{\prime}{ }^{\prime}$ are positive design constants that determine the closed-loop dynamics. To $\mathrm{V}^{\prime}<0$, the stabilizing virtual controls are chosen as

$$
\begin{aligned}
& i_{s q}^{*}=\frac{1}{k_{t} \psi_{r d}}\left\lfloor k_{\omega} \varepsilon_{\omega}+\frac{d \omega_{r}^{*}}{d t}+\frac{T_{l}}{J}+B \omega_{r}+k_{\omega}^{\prime}\left(\omega_{r}^{*}-\omega_{r}\right)\right] \\
& i_{s d}^{*}=\frac{\tau_{r}}{L_{m}}\left[k_{\psi} \varepsilon_{\psi}+\frac{d \psi_{r d}^{*}}{d t}+\frac{1}{\tau_{r}} \psi_{r d}+k_{\psi}^{\prime}\left(\psi_{r d}^{*}-\psi_{r d}\right)\right]
\end{aligned}
$$

We obtain:

$$
\frac{d V_{(\omega, \psi)}}{d t}=-k_{\omega} \varepsilon_{\omega}^{2}-k_{\psi} \varepsilon_{\psi}^{2}<0
$$

\section{2 The inner current loop controllers using PCH}

In contrast, unlike the speed controllers, requiring with the inner current loop are fast response and highly robust and stable. To meet these control criteria, internal current controller is proposed using $\mathrm{PCH}$ control. This controller can effectively compensate for load disturbance in the system so the proposed method is more robust, stability and faster dynamics response. A PCH system with dissipation is a representation of the form:

$$
\left\{\begin{array}{l}
\frac{d x}{d t}=[J(x)-R(x)] \frac{d H}{d x}(x)+g(x) u \\
y=g^{T}(x) \frac{d H}{d x}(x)
\end{array}\right.
$$

where $R_{x}=R_{x}^{T}>0 \quad$ represents the dissipation. The interconnection structure is captured in matrix $g(x)$ and the skew symmetric matrix $J_{x}=-J_{x}^{T}, H(x)$ is the total stored energy function of the system. We define the state vector, input vector and output vector are as follows, respectively

$\left\{\begin{array}{l}x=\left[\begin{array}{ll}x_{1} & x_{2}\end{array}\right]^{T}=\left[\begin{array}{ll}L_{s} i_{s d} & L_{s} i_{s q}\end{array}\right]^{T} \\ u=\left[\begin{array}{ll}u_{1} & u_{2}\end{array}\right]^{T}=\left[\begin{array}{ll}b R_{r} \psi_{r d}+c u_{s d} & -b \omega_{r} \psi_{r d}+c u_{s q}\end{array}\right]^{T} \\ y=\left[\begin{array}{ll}i_{s d} & i_{s q}\end{array}\right]^{T}\end{array}\right.$

The Hamiltonian function of the system is given by 


$$
H(x)=\frac{1}{2} x^{T} D^{-1} x=\frac{1}{2}\left(x_{1}^{2}+x_{2}^{2}\right)=\frac{1}{2}\left(L_{s} i_{s d}^{2}+L_{s} i_{s q}^{2}\right)
$$

Suppose we wish to asymptotically stabilize the system (23) around a desired equilibrium xo, a closed-loop energy function $\mathrm{Hd}(\mathrm{x})$ is assigned to the system which has a strict minimum at $\mathrm{x} 0$ (that is, $\mathrm{Hd}(\mathrm{x})>\mathrm{Hd}(\mathrm{x} 0)$ for all $\mathrm{x} \neq \mathrm{x} 0$ in a neighborhood of $\mathrm{x} 0)$. The feedback stabilization theory of $\mathrm{PCH}$ system is given as follows [17]. Given $\mathrm{J}(\mathrm{x}), \mathrm{R}(\mathrm{x})$, $\mathrm{H}(\mathrm{x}), \mathrm{g}(\mathrm{x})$ and the desired equilibrium xo. Assume we can find a feedback control $\mathrm{u}=\alpha(\mathrm{x}), \mathrm{R}_{\mathrm{a}}(\mathrm{x}), \mathrm{J}_{\mathrm{a}}(\mathrm{x})$ and a vector function $\mathrm{K}(\mathrm{x})$ satisfying:

$$
\begin{aligned}
& \frac{d K}{d x}(x)=\left[\frac{d K}{d x}(x)\right]^{T} ; K\left(x_{0}\right)=-\frac{d H}{d x}\left(x_{0}\right) ; \\
& \frac{d K}{d x}\left(x_{0}\right)>\frac{d^{2} H}{d^{2} x}\left(x_{0}\right)
\end{aligned}
$$

The closed-loop system:

$$
\frac{d x}{d t}=\left[J_{d}(x)-R_{d}(x)\right] \frac{d H_{d}}{d x}(x)
$$

will be a PCH system with dissipation.

$$
K(x)=\frac{d H_{a}}{d x} ; H_{a}(x)=H_{d}(x)-H(x)
$$

where $H_{a}$ is the energy added to the system and $\mathrm{x}_{0}$ will be a stable equilibrium of the closed-loop system. The expected Hamiltonian energy storage function is defined as

$$
\begin{aligned}
& H_{d}(x)=H(\Delta x)=H\left(x-x_{o}\right) \\
& J_{d}(x)=J(x)+J_{a}(x)=-J_{d}^{T}(x) \\
& R_{d}(x)=R(x)+R_{a}(x)=R_{d}^{T}(x)>0 \\
& J_{a}(x)=\left[\begin{array}{cc}
0 & J_{1} \\
-J_{1} & 0
\end{array}\right] ; \quad R_{a}(x)=\left[\begin{array}{cc}
r_{1} & 0 \\
0 & r_{2}
\end{array}\right]
\end{aligned}
$$

where, $\mathrm{J} 1$, r1 and $\mathrm{r} 2$ are undetermined interconnect and damping parameters. According to equations (25)-(30), the controller of the current inner loop of the motor is

$$
\left\{\begin{array}{l}
u_{s d}^{*}=\sigma\left[a i_{s d}+r_{1}\left(i_{s d}^{*}-i_{s d}\right)-J_{1}\left(i_{s q}^{*}-i_{s q}\right)-L_{s} \omega_{s} i_{s q}-b R_{r} \psi_{r d}\right] \\
u_{s q}^{*}=\sigma\left[a i_{s q}+r_{2}\left(i_{s q}^{*}-i_{s q}\right)+J_{1}\left(i_{s d}^{*}-i_{s d}\right)+L_{s} \omega_{s} i_{s d}+b \omega_{r} \psi_{r d}\right]
\end{array}\right.
$$

\subsection{Structure of the NN_SC_ MRAS Speed Observer}

In this scheme, the measured stator current components are also used as the reference model of the MRAS observer to avoid the use of a pure integrator and reduce influence of motor parameter variation as in [25]. An Artificial Neural Network $(\mathrm{ANN})$ can reproduce the equation (31), where $w_{l}$, $w_{2}, w_{3}, w_{4}$ are the weights of the neural networks defined as (31);

$$
\begin{aligned}
& \hat{i}_{s D}(k)=w_{1} \hat{i}_{s D}(k-1)+w_{2} u_{s D}(k-1)+w_{3} \hat{\psi}_{r Q}(k-1)+w_{4} \hat{\psi}_{r D}(k-1) \\
& \hat{i}_{s Q}(k)=w_{1} \hat{i}_{s Q}(k-1)+w_{2} u_{s Q}(k-1)+w_{3} \hat{\psi}_{r D}(k-1)+w_{4} \hat{\psi}_{r Q}(k-1)
\end{aligned}
$$

where :

$$
w_{1}=1-\frac{T_{s} R_{s}}{\sigma L_{s}}-\frac{\tau_{s} L_{m}^{2}}{\sigma L_{s} L_{r} \tau_{r}} ; w_{2}=\frac{T_{s}}{\sigma L_{s}} ; w_{3}=\frac{T_{s} L_{m}}{\sigma L_{s} \tau_{r}} ; w_{4}=\frac{T_{s} L_{m} \omega_{r}}{\sigma L_{s} L_{r}}
$$

where: $i^{\wedge}{ }_{(\mathrm{k})}$ the current variables estimated with the adaptive model and $\mathrm{k}$ is the current time sample, $R_{s}$, $L_{s}, L_{r}, L_{m}$ are stator resistance and stator, rotor, magnetizing inductances, respectively. $T_{s}$ is the sampling time for the stator current observer.
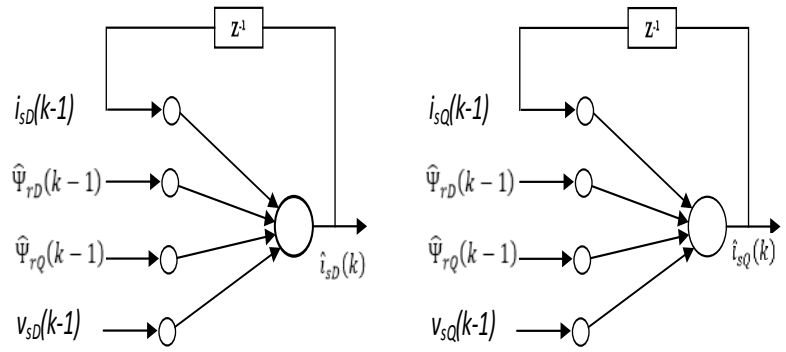

Figure 5. NN VM SC_MRAS based observer (a) $\alpha$-axis (b) $\beta$-axis

A two layer linear $\mathrm{NN}$, that with weights as defined as shown in Fig. 5, can represent equation (31) and represent the adaptive model for the $\mathrm{SC}_{-}$ MRAS scheme where $\mathrm{w}_{1}$ and $\mathrm{w}_{4}$, which contain $\mathrm{R}_{\mathrm{s}}$ and the rotor speed information respectively, are adjusted online in such a way as to minimize the error between actual and estimated currents. Since rotor flux estimation is required for the $\mathrm{SC}$ MRAS scheme, in this proposal observer, rotor flux has estimated by VM. The block diagram of the NNbased stator current MRAS scheme using a VM rotor flux observer is shown in Fig. 6. The performance of VM rotor flux observer has been improved significantly with $\mathrm{Rs}$ value updated online.

\subsubsection{Rotor Speed Estimation Algorithm}

In onder to derive the weight adjustment law of the NN stator current observer, define the energy function $\mathrm{E}$ to be minimised:

$$
E=\frac{1}{2} \varepsilon_{i}^{2}(k)
$$

where :

$$
\begin{aligned}
\varepsilon_{i}(k) & =i_{s}(k)-i_{s}(k)=\left[\begin{array}{ll}
i_{s D}(k)-i_{s D}(k) & i_{s Q}(k)-i_{s Q}(k)
\end{array}\right] \\
& =\left[\begin{array}{ll}
\varepsilon_{i D}(k) & \varepsilon_{i Q}(k)
\end{array}\right]^{T}
\end{aligned}
$$


The weight adjustment has to be proportional to the negative of the error gradient to obtain a minimum squared error between actual and estimated stator current.

$$
\frac{\partial E}{\partial w_{4}}=\frac{\partial E}{\partial \hat{i}_{s}(k)} \frac{\partial \hat{i}_{s}(k)}{\partial w_{4}}
$$

where:

$$
\begin{aligned}
& \frac{\partial E}{\partial \hat{i}_{s}(k)}=\frac{1}{2} \frac{\partial}{\partial \hat{i}_{s}(k)}\left[i_{s}(k)-\hat{i}_{s}(k)\right]^{2}=-\varepsilon_{i}^{T}(k) \\
& \frac{\partial \hat{i}_{s}(k)}{\partial w_{4}}=\left[\begin{array}{ll}
\hat{\psi}_{r Q}(k-1) & -\hat{\psi}_{r D}(k-1)
\end{array}\right]^{T} \\
& \quad \text { Substituting }(15) \text { and }(16) \text { into }(14): \\
& -\frac{\partial E}{\partial w_{4}}=\varepsilon_{i D}(k) \hat{\psi}_{r Q}(k-1)-\varepsilon_{i Q}(k) \hat{\psi}_{r D}(k-1)
\end{aligned}
$$

The weight adjustment law of the NN_VM_SC_ MRAS observer can be derived based on backpropagation network (BPN) algorithm and can be written:

$$
\begin{aligned}
\Delta w_{4}(k) & =-\eta \frac{\partial E}{\partial w_{4}} \\
& =-\eta\left[\varepsilon_{i D D}(k) \hat{\psi}_{r Q}(k-1)-\varepsilon_{i s Q}(k) \hat{\psi}_{r D}(k-1)\right]
\end{aligned}
$$

where $\eta$ is a positive constant called the learning rate. Hence the weight update equation:

$$
w_{4}(k)=w_{4}(k-1)+\Delta w_{4}(k)+\alpha \Delta w_{4}(k)
$$

where $\alpha$ is a positive constant called the momentum constant. Due to simple structure of the NN stator current observer, the weight adjustment can be performed online and the motor speed can be estimated from the weight $\mathrm{w}_{4}$ as:

$$
\hat{\omega}_{r}(k)=\frac{\sigma L_{s} L_{r}}{T_{s} L_{m}} w_{4}(k)
$$

\subsubsection{Rotor Flux and Stator Resistance Online Estimation Algorithm.}

\subsubsection{Rotor Flux identifier}

In this proposed observer, the rotor flux components are identified base on VM equation (42) to generate the estimated rotor flux value what are provided for the adaptive model of the proposed observer.

$$
\begin{aligned}
& \frac{d \psi_{r D}}{d t}=\frac{x_{r}}{x_{m}}\left(v_{s D}-R_{s} i_{s D}-\sigma T_{n} x_{s} p i_{s D}\right) \\
& \frac{d \psi_{r Q}}{d t}=\frac{x_{r}}{x_{m}}\left(v_{s Q}-R_{s} i_{s Q}-\sigma T_{n} x_{s} p i_{s Q}\right)
\end{aligned}
$$

\subsubsection{Stator Resistance Estimator}

From (32), (33) to minimize squared error between actual and estimated stator current the weight adjustment has to be proportional to the negative of the error gradient with respect to the weight. It can be written as:

$$
w_{1}(k)=w_{1}(k-1)+\Delta w_{1}(k)+\gamma \Delta w_{1}(k)
$$

where

$$
\begin{aligned}
& \Delta w_{1}(k)=-\beta \frac{\partial E}{\partial w_{1}} \\
& =-\beta\left[\varepsilon_{i s D}(k) \hat{i}_{s D}(k-1)+\varepsilon_{i s Q}(k) \hat{i}_{s Q}(k-1)\right]
\end{aligned}
$$

where $\gamma$ is a positive constant called the momentum constant, $\beta$ is a positive constant called the learning rate. Due to simple structure of the NN stator current observer, the weight adjustment can be performed online and the stator resistance can be estimated from the weight $\mathrm{w} 1$ as:

$$
\hat{R}_{s}(k+1)=\frac{\sigma L_{s}}{T_{s}}\left[1-\frac{T_{s} L_{m}^{2}}{\sigma L_{r} L_{s} T_{r}}-w_{1}(k+1)\right]
$$

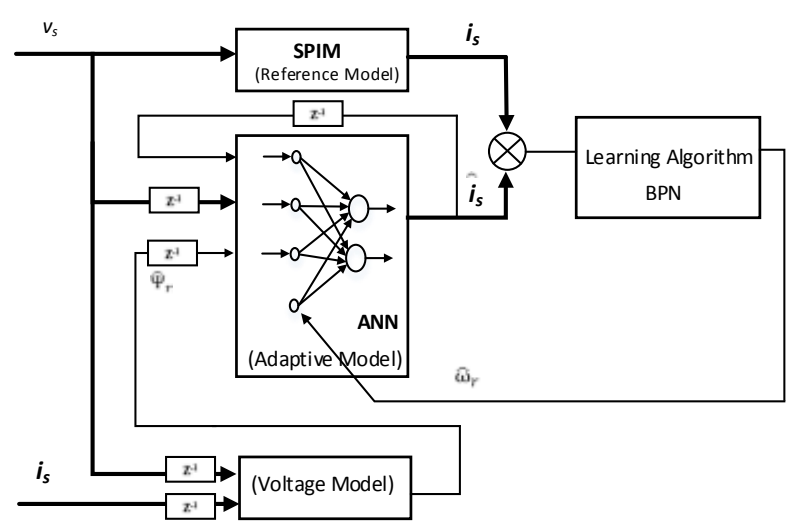

Figure 6. The proposed SC_ MRAS speed observer

\section{Simulink and Discussion}

In this part, the performance verification of proposed scheme of SPIM drive the propulsion system of EV as shown in Fig. 4 is carried out through Matlab simulation software. These surveys are implemented based benchmark tests in [26-28]. SPIM parameters: $1 \mathrm{HP}, 220 \mathrm{~V}, 50 \mathrm{~Hz}, 4$ pole, 1450 rpm. $\mathrm{Rs}=10.1 \Omega, \mathrm{Rr}=9.8546 \Omega, \mathrm{Ls}=0.833457 \mathrm{H}$, $\mathrm{Lr}=0.830811 \mathrm{H}, \mathrm{Lm}=0.783106 \mathrm{H}, \mathrm{Ji}=0.0088$ kg.m2. Rs is nominal value of stator resistance.

\section{The first case:}

+ Test 1: Command to set the reference speed: The speed was increased from $0 \mathrm{rpm}$ to $270 \mathrm{rpm}$, after $5 \mathrm{~s}$ the speed reduced from 270 to $135 \mathrm{rpm}$ and increased again to $270 \mathrm{rpm}, 100 \%$ rated load is applied (based on the test in [26, Fig 5 abc]. (Fig 7a).

+ Test 2: In this test, an improved ECE-15 cycle based on [26, Fig 2] was performed. A European 
standard test driving cycle with data points representing the vehicle reference speed over time. It is characterized by low vehicle speed (maximum of $50 \mathrm{~km} \mathrm{/} \mathrm{h)} \mathrm{and} \mathrm{it} \mathrm{is} \mathrm{suitable} \mathrm{electric} \mathrm{vehicle}$ testing in urban areas. ( Fig 7b).

+ Test 3: This survey is conducted with a sample cycle similar to the survey 2 but based on [27, Fig 8] with the extended survey time with 5 test cycles. as in [27]. The test performed on EVs based on ECE15 test cycle. The goal of this test is to evaluate the performance and dynamic response of the sensorless vector control using BS_PCH in combination with proposed observer when applying for the propulsion system in EV for 5 consecutive cycles to prove the control quality, stability, robustness of the control and estimation strategies. The test cycle is the urban
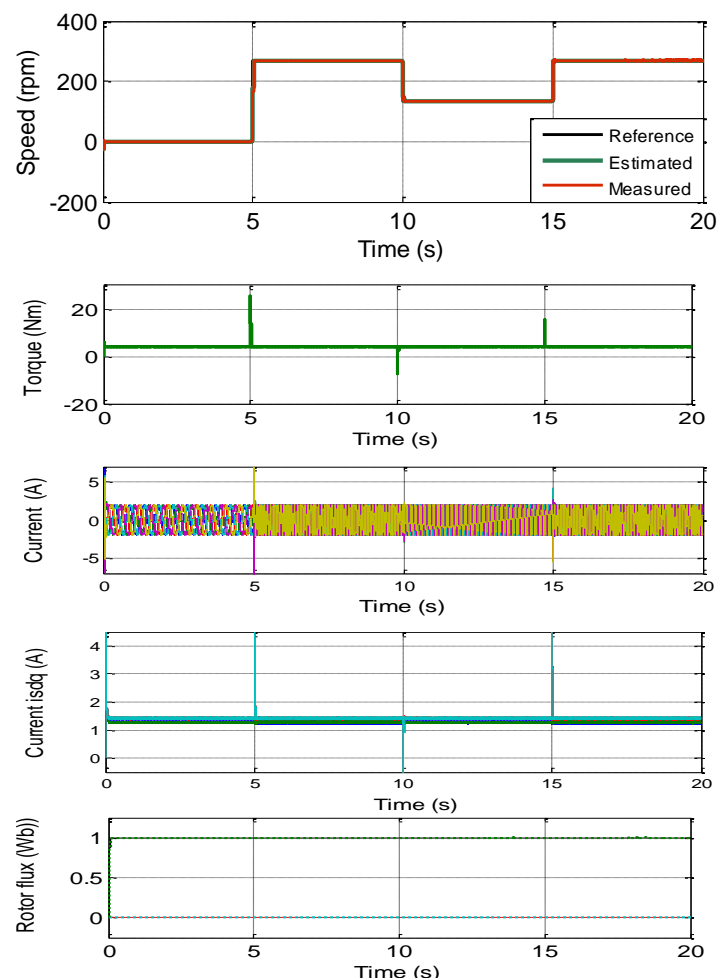

a.

Fig. 7 Speed, stator current, torque response and estimation error:

a. First test cycle with reference speed: 0-270-135-270 rpm. [26, Fig. 5 abc, ghi]).

b. Second test cycle: Modified ECE-15 (Fig. 8) [26, Fig. 2].

Observing the simulation results shown in Fig. 6, we see that the NN_SC_MRAS speed observer works correctly and stably, the estimated speed is almost exactly equal to the reference and measured speed, in both the established and transient mode, even at zero and low speed regions.

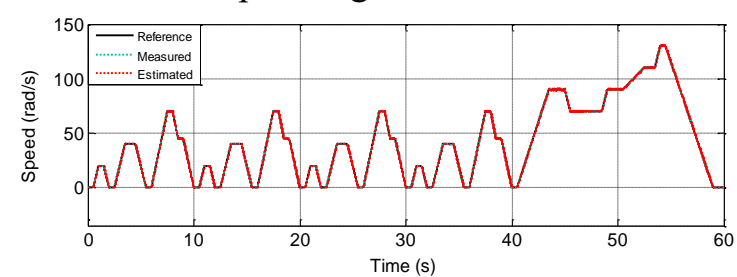

ECE-15 cycle [27]. From the simulation results show in Fig 5, it is easy to see that the speed responses in both tests 1 and 2 in case 1 is very good, the speed error is nearly zero in the stable mode. BS_PCH controller can provide very good dynamic response during acceleration and deceleration of EV.

Test 3 performed on EVs based on ECE-15 test cycle. The goal of this test is to evaluate the performance and dynamic response of the sensorless vector control using $\mathrm{BS} \mathrm{PCH}$ in combination with proposed observer when applying for the propulsion system in EV for 5 consecutive cycles to prove the control quality, stability, robustness of the proposed control and estimation strategies.
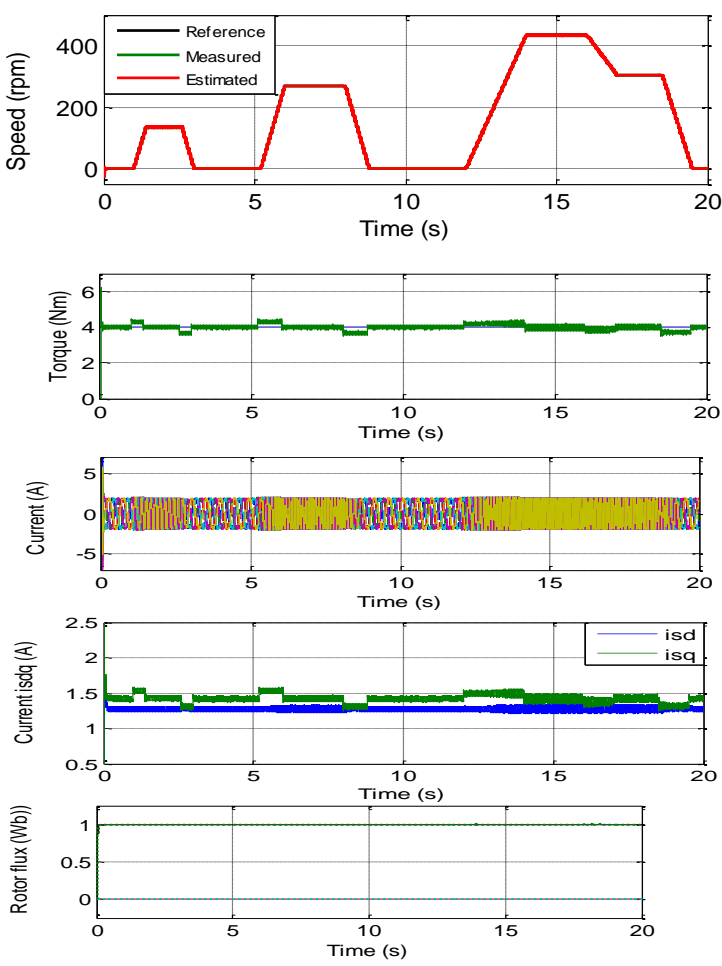

b.

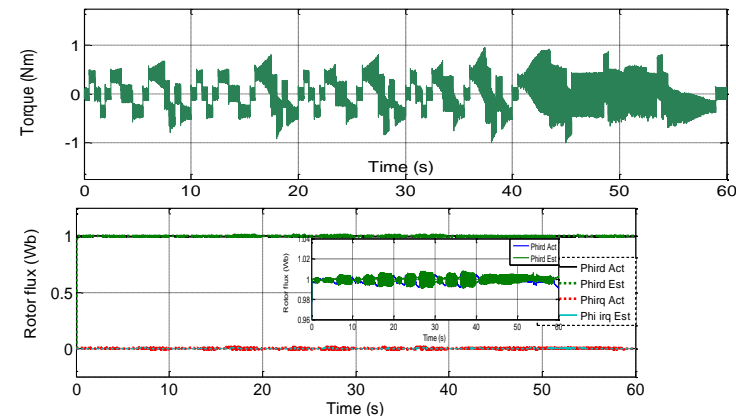

Fig. 8 Speed, stator current, torque response, estimated error in the third test cycle based on [27]. 


\section{Case 2:}

Tests verify and evaluate the performance of the proposed SPIM drive using in EV based on recommended benchmark tests in [28, Fig.6] also make with describe the road during the test EV operation as shown in Fig. 9.

The survey results shown in Fig. 10 verified the effectiveness of the proposed drive for the wheel using SPIM. This proposed scheme provide fast, accurate speed and torque responses, control and estimation quality are very good during both stability and dynamic modes. it is suitable the requirements of the propulsion system of EV.

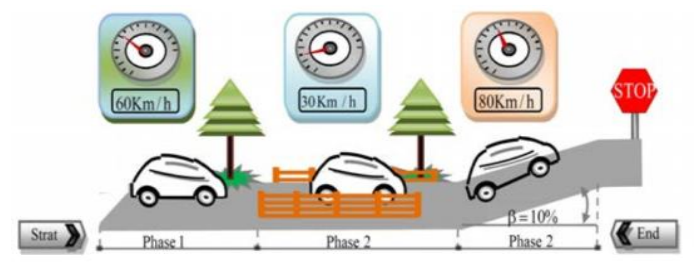

Fig. 9 Describe the road during the test EV operation[28]
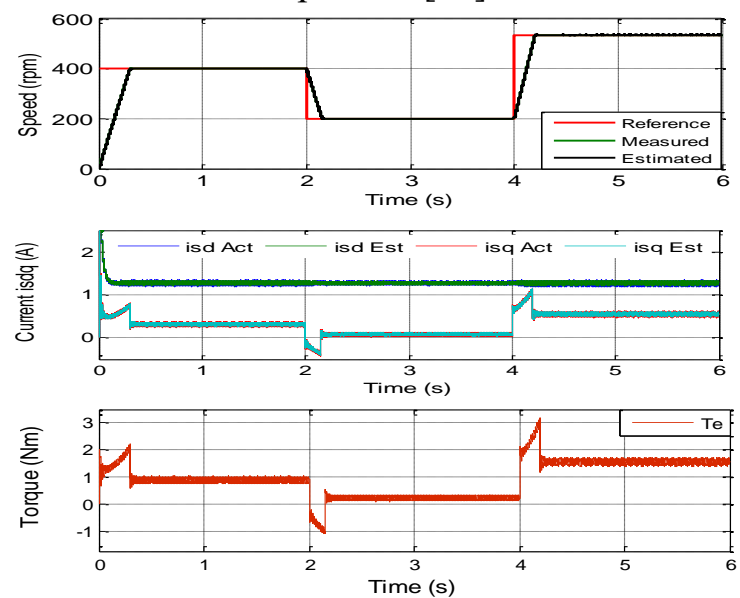

Fig. 10 Speed, estimation error, stator current, torque response in during the $\mathrm{EV}$ test operation based on test in [140, Fig.6].

\section{Conclusion}

This paper are proposed a sensorless vector control scheme for the in-wheel motor drive system of Electric Vehicle (EV) using a new controlle structure combined with a stator current MRAS based on adaptive speed observer using neuron network. The simulation results are performed to prove the successful development of the proposed sensorless vector control scheme of SPIM drives for the propulsion system of electric vehicle. The speed of SPIM proving for EV follows accurately the reference speed set commands, instantaneous torque response. The proposed scheme meets the requirements of the propulsion system of $\mathrm{EV}$, even at zero and low speed regions. In fact, electric vehicle performance is greatly influenced by the quality of the vehicle's control system, electric motor,... the application of modern control techniques to improve and enhance the performance of electric vehicles have high practical significance.

\section{References}

[1] C. C. Chan et al., "Electric vehicles charge forward," IEEE Power Energy Mag., Nov./Dec. 2004, Vol. 2, pp. 24-33.

[2] V. Erginer, M. H. Sarul, "High Performance and Reliable Torque Control of Permanent Magnet Synchronous Motors in Electric Vehicle Applications", Elektronika ir Elektrotechnika, 2013, Vol. 19, pp. 41-46.

[3] I. Husain, "Electric and hybrid vehicles: design fundamentals", CRC press, 2011.

[4] C. C. Chan, "The state of the art of electric and hybrid vehicles," Proc. IEEE, Feb. 2002, Vol. 90, pp. 247-275.

[5] A. Haddoun1,2, M.E.H. Benbouzid1, D. Diallo3, R. Abdessemed4, J. Ghouili5 and K. Srairi "Comparative Analysis of Estimation Techniques of SFOC Induction Motor for Electric Vehicles", Proceedings of the 2008 International Conference on Electrical Machines, Oct, 2018.

[6] S. Woosuk, S. Jincheol, and J. Yu-seok, "Energy-Efficient and Robust Control for HighPerformance Induction Motor Drive With an Application in Electric Vehicles," IEEE Transactions on Vehicular Technology, 2012, Vol. 61, pp. 3394-3405.

[7] Farid Khoucha, Khoudir Marouani, Abdelaziz Kheloui, Mohamed Benbouzid. "A Sensorless Direct Torque Control Scheme Suitable for Electric Vehicles," Electromotion, 2009, Vol. 16, pp.89-97.

[8] J. W. Finch and D. Giaouris, "Controlled AC electrical drives," IEEE Trans. Ind. Electron., Feb. 2008, Vol. 55, pp. 481-491.

[9] W. Leonhard, Control of Electrical Drives: Springer, 2001.

[10] Hamou Ait Abbasa, Mohammed Belkheirib, Boubakeur Zegninia, Feedback Linearization Control of An Induction Machine Augmented by Single Hidden Layer Neural Networks, International Journal of Control, 2015, Vol. 89, pp.140-155.

[11] Oscar Barambones, Patxi Alkorta, Aitor J. Garrido, I. Garrido and F.J. Maseda, "An adaptive sliding mode control scheme for induction motor drives, International Journal of Circuits, Systems And Signal Processing, 2007, Issue 1, Vol. 6, pp. 73-78. 
[12] Mehazzem F, Nemmour AL, Reama A, Benalla H. "Nonlinear integral backstepping control for induction motors". In: Proceedings of 2011 International Aegean Conference on Electrical Machines and Power Electronics and Electromotion, Joint Conference, 2011, Turkey.

[13] M.R Jovanovic, B. Bamieh, "Architecture Induced by Distributed Backstepping Design", IEEE Transactions on Automatic Control, Jan 2007, Vol. 52, pp. 108 - 113.

[14] Yassine Kali, Magno Ayala 2, Jorge Rodas 2 , Maarouf Saad 1, Jesus Doval-Gandoy 3, Raul Gregor 2 and Khalid Benjelloun 4, "Current Control of a Six-Phase Induction Machine Drive Based on Discrete-Time Sliding Mode with Time Delay Estimation" Energies, 2019, 12(1).

[15] Moulay Rachid Douiri, Mohamed Cherkaoui, and Ahmed Essadki, "Genetic Algorithms Based Fuzzy Speed Controllers for Indirect Field Oriented Control of Induction Motor Drive Moulay Rachid Douiri, Mohamed Cherkaoui, and Ahmed Essadki", International Journal of Circuits, Systems And Signal Processing, 2012, Issue 1, Volume 6, pp. 21-28.

[16] I. Gonzalez-Prieto, M.J. Duran, J.J. Aciego, C. Martin, F. Barrero, "Model Predictive Control of Six-phase Induction Motor Drives Using Virtual Voltage Vectors" IEEE Trans. Indust.Electronics, 2018, Vol. 65(1).

[17] Zhiping Cheng, Liucheng Jiao, Hamiltoniaian Modeling and Passivity-based Control of Permanent Magnet Linear Synchronous Motor, Journal Of Computers, February 2013, Vol. 26, pp. 501-508.

[18] Abderrahmen Zaafouri, Chiheb Ben Regaya, Hechmi Ben Azza, Abdelkader Châari, "zDSPbased adaptive backstepping using the tracking errors for high-performance sensorless speed control of induction motor drive", ISA Transactions., 2016, Vol. 60, pp. 333-347.

[19] Q. Su, W. Quan, G. Cai, et al., Improved adaptive backstepping sliding mode control for generator steam valves of non-linear power systems, IET Control Theory Appl., 2017, Vol. 11 , pp. 1414-1419.

[20] Z. Liu, B. Chen, C. Lin, Adaptive neural backstepping for a class of switched nonlinear system without strict-feedback form, IEEE Trans. Syst. Man Cybern. Syst., 2017, Vol. 47 , pp.1315-1320.

[21] H. Li, L. Wang, H. Du, et al., Adaptive fuzzy backstepping tracking control for strict-feedback systems with input delay, IEEE Trans. Fuzzy Syst., 2017, Vol. 25 , pp. 642-652.
[22] 22Flah A, Novak M, Lassaad S. An Improved Reactive Power MRAS Speed Estimator With Optimization for a Hybrid Electric Vehicles Application. J. Dyn. Syst. Meas. Control., 2018, Vol. 140, pp.061 016.

[23] E. Levi, Multiphase electric machines for variable-speed applications, IEEE Transactions on Industrial Electronics. , 2008, Vol 55, pp. $1893-1909$.

[24] Huang, Q., Huang, Z., Zhou, H, "Nonlinear optimal and robust speed control for a lightweighted all-electric vehicle", IET Control Theory Appl., 2007, Vol. 3, pp. 437-444.

[25] Ngoc Thuy Pham, Diep Phu Nguyen, Khuong Huu Nguyen, Nho Van Nguyen, "A Novel Neural Network SC_MRAS Based Observer for High-Performance", International Journal of Intelligent Engineering and Systems (ISSN: 2185-3118), Dec-2018, Vol 11( 6), pp.95-107.

[26] Abdelhakim Haddoun, Mohamed Benbouzid, Demba Diallo, Rachid, Abdessemed, Jamel Ghouili, Kamel Srairi, "Modeling, Analysis, and Neural Network Control of an EV Electrical Differential", IEEE transactions on industrial electronics, june 2008, Vol. 55, pp. 2286 - 2294.

[27] F.-J. Lin, Y.-C. Hung, J.-C. Hwang,I.-P. Chang, M.-T. Tsai, "Digital signal processorbased probabilistic fuzzy neural network control of in-wheel motor drive for light electric vehicle" IET Electr. Power Appl.,2012, Vol. 6, pp. 47-61

[28] BrahimGasbaoui,AbdelfatahNasri,Othmae Abdelkhalek, “An Efficiency PI Speed Controller for Future Electric Vehicle in Several Topology". Procedia Technology, 2016, Vol. 22, pp. 501508.

\section{Creative Commons Attribution License 4.0 (Attribution 4.0 International , CC BY 4.0)}

This article is published under the terms of the Creative Commons Attribution License 4.0 https://creativecommons.org/licenses/by/4.0/deed.en US 